\title{
Investigating the Relationship Between U.S. Jamaican Immigrants' Cultural Beliefs and Conflict Management Styles with Job Satisfaction and Job Performance
}

\author{
Keisha Hill-Grey \\ Florida International University \\ Thomas G. Reio, Jr. \\ Florida International University \\ Tonette S. Rocco \\ Florida International University
}

\begin{abstract}
This cross-sectional study $(N=135)$ examined the links between cultural beliefs, conflict management styles, job satisfaction and job performance. An internet-based self-report survey was completed by U.S. Jamaican immigrants from Florida and New York. Job satisfaction was positively related to task and contextual performance. Conflict management style was linked to satisfaction and performance. The moderated regression analyses revealed that job satisfaction was a more powerful predictor of job performance in the presence of the compromising conflict management style. Organizational research designed to further validate this study's conceptual models was recommended in new international settings with other Jamaican immigrant groups.
\end{abstract}

Keywords: job satisfaction, job performance, conflict management, cultural beliefs, human resource development

\section{INTRODUCTION}

In a world where dire environmental contingencies can arise without warning, organizations must be creatively adept at handling the rapid change these contingencies provoke (Wang, Anne, \& McLean, 2016). One of the current major contingencies for nations is both the acute and ongoing pressures associated with dealing effectively and fairly with the influx of immigrant populations. In the communities where they settle, immigrants too often have little sense about how to fit in with their new culture, despite their best intentions, resulting in all-too-predictable interpersonal conflict among themselves and with "natives" (Brunetta \& Reio, 2016). Likewise, in workplace settings, immigrant or foreign workers are often faced with daunting new customs, rules, procedures, and ways of behaving within cultural norms with not only coworkers in teams and cross-functional workgroups, but also supervisors and those outside the organization (e.g., vendors) (Leung, Wang, \& Smith, 2010). 
The state of workplace affairs where immigrant or foreign worker customs, values and behaviors do not align with the dominant workplace cultures' attitudinal and behavioral norms sets the stage for the miscommunications and misunderstandings that undergird workplace conflict (Rahim, 2011). Conflict and the individual style in which it is managed (i.e., conflict management style), in turn, should be of great concern to organizations. This is because although it can be associated with positive organizational outcomes (e.g., better group problem solving, cohesiveness, loyalty; Baron, 1991), the extant research demonstrates how conflicts are typically linked with significant negative outcomes like poorer job satisfaction, organizational commitment, organizational citizenship behavior and job performance, and greater turnover intent (e.g., Barki \& Hartwick, 2001; De Dreu \& Weingart, 2003). Each of the aforementioned negative outcomes are detrimental and therefore costly largely because they do not support organizational efforts toward being more efficient, quality-oriented, innovative, or responsive to customers, the four generic building blocks of competitive advantage (Ferguson \& Reio, 2010; Porter, 1985).

Organizational researchers and practitioners can play an important role in promoting a workplace that eschews conflict and its negative workplace outcomes and instead supporting positive outcomes (Reio \& Trudel, 2013). For example, human resource (HR) professionals could provide individuals through training and development activities the information and knowledge needed to foster better understandings of diverse conflict management styles (CMS) and how they can be influenced by cultural beliefs (De Dreu \& Beersma, 2005). This new knowledge and understanding connecting conflict and CMS with culture could provide individuals with the conflict management strategy skills needed to deal effectively with differing cultural beliefs and CMS, thereby possibly reducing the likelihood of counterproductive conflict (Reio \& Trudel). We must remember if organizational leaders do not address negative workplace conflict successfully, this same workplace conflict can be the precursor to future conflict (Trudel \& Reio, 2011). Unfortunately, there is insufficient research to guide organizational researchers when it comes to understanding the links between cultural beliefs, conflict, CMS and negative organizational outcomes, especially among those from different immigrant groups (Rahim, 2011). Consequently, the purpose of this study was to investigate the relationships between cultural beliefs and CMS, and their associations with two important organizational outcomes; that is, job satisfaction and job performance.

\section{Background Literature}

Although there are large populations of Jamaicans in Canada, the U.K. and the Caribbean overall, we focus on the U.S. immigrant population. We focus our efforts in the U.S. because so little psychological, sociological, or organizational research has been done on Jamaican immigrants in the U.S., despite housing one of the largest groups of Jamaicans outside Jamaica (Ferguson, Bornstein, \& Pottinger, 2012).

The 2010 American Community Survey (2011) indicated there are 309.3 million persons living in the U.S., including 40.0 million immigrants. The number of immigrants living in the U.S. has increased by 8.8 million in the last ten years, and immigrants now account for $13 \%$ of the U.S. population. Of the 40 million immigrants in the U.S., 21.2 million come from Latin America and the Caribbean, which is a little over half of the immigrant population. U.S. Jamaican immigrants, most who are voluntary choice immigrants, account for $61 \%$ of the U.S. Caribbean immigrant population (U.S. Census, 2011). Like other voluntary immigrants (Ogbu 1993), the move to the U.S. for many Jamaican immigrants allows them more economic stability and greater political freedom (Hall, 2010).

\section{Cultural Beliefs}

Very little research exists on this population, and more studies are needed to understand their experiences working in the U.S. workforce. As Jamaican immigrants enter the U.S. workforce, they carry with them their culture and distinct cultural beliefs that may differ from their U.S. counterparts. Cultural beliefs are the basic premises that people endorse and use to guide their behavior in different situations (Leung, Bond, de Carrasquel, Muñoz, et al., 2002). These are not based on scientific validations, but on the personal experiences and socialization of individuals. Cultural groups have their own cultural beliefs 
or social axioms that they use to guide their behaviors. The term social axioms will be used interchangeably with cultural beliefs.

Social axioms, introduced by Leung et al. (2002), break individual beliefs into five dimensions. The five dimensions include: (a) control by fate: a belief in predetermined life outcomes, which can be altered by people; (b) reward for application: a belief that if one works hard, one will be rewarded; (c) social flexibility: the belief that human behavior is unpredictable and cannot be restricted by rigid rules; (d) social cynicism: the overall belief that people and institutions cannot be trusted; and (e) spirituality: the belief in religion and/or a higher power. These dimensions include characterizing beliefs that relate to social behaviors across contexts, actors, targets and time (Leung et al., 2002). Further, beliefs have an impact on how people behave in a conflict, which is influenced by access to resources and how those resources are used.

Cultural beliefs can have a direct relation with how individuals handle and experience conflict. In organizations, individuals get into conflict with others when their perceptions and the reality of their relationships with other employees do not concur, and when they, for instance, disagree with the distribution and allocation of resources (De Dreu \& Beersma, 2005). Conflict is what happens when an individual or group gets what they want and the other party does not, based on differences or perceived differences about resources, interests, beliefs, values, or practices that matter to an individual (Rahim, 2010). There are distinct patterns with how individuals manage conflict and these are referred to as conflict management styles (Kaushal \& Kwantes, 2006).

\section{Conflict Management Styles}

There are CMS that vary by individual preference and cultural group membership and are based on an individual's socialization (Hofstede, 1980; Kaushal \& Kwantes, 2006). Rahim (1983) identified five different styles that people use when managing interpersonal conflict with superiors, subordinates, and peers. These are integrating, obliging, dominating, avoiding, and compromising.

Employees who dominate during a conflict have a high concern for self and low concern for others, and are focused on their own interests, tending to have little regard for the others' needs (Rahim, 1983a). In obliging (also known as accommodating), the employee has a low concern for self and high concern for others and neglects what they need in the conflict, becoming more concerned with the other person's needs and making sure that they get what they need (Rahim, 2011).

Individuals who engage in an integrate CMS (engage in problem solving) have a high concern for self and others. These individuals are usually cooperative and attempt to obtain a solution in which both parties are winners. They do this while using open communication, clearing up misunderstandings, and analyzing the underlying causes of conflict (Rahim, 2011).

Individuals who employ an avoid style tend to avoid conflict and have a low concern for self and others. They tend to walk away from the conflict situation and limit direct interaction with the person or persons with whom they might be in conflict; in some cases, they might suppress the conflict (Meyer, 2004) which fails to satisfy the needs of either party involved (Rahim, 2010). Individuals who utilize the compromising CMS usually have an intermediate concern for self and others (Rahim, 2011). Integrating is often the preferred CMS when dealing with interpersonal conflict.

The type of CMS an individual uses to manage a conflict has been linked to whether the outcome is positive, negative and successful (Rahim, Antonioni, \& Psenicka, 2001). A negative outcome of not resolving a workplace conflict includes lower organization productivity (Chan, Huang, \& $\mathrm{Ng}, 2008$ ), which can dampen employee relationships, goal achievement, job performance, job satisfaction (Rahim, 2011), and employee learning (Staw, 1980). Positive outcomes from successfully resolving a conflict include improved individual and group performance, and employees becoming more innovative and better at problem solving (Rahim et al., 2001). Integrating conflict management style has been identified as being more effective at successfully handling conflict (Burke, 1970), meaning yielding positive outcomes. On the other hand, dominating and avoiding CMS have been associated with ineffective conflict management styles (Burke, 1970). 
An integrating CMS has been associated with increased levels of job satisfaction of employees (XiaoHong, Zhao, Liu, \& Desheng Dash, 2012). Job satisfaction consists of an individual's over-all attitude toward all aspects of the job and 'an evaluative judgment about one's job that partly, but not entirely, results from emotional experiences at work' (Weiss \& Cropanzano, 1996). Increased job satisfaction is known to be linked to lower levels of employee stress, prevent staff shortages and cut costs in the organization; specifically related to, for example, conflict management training (Staw, 1980).

On the other hand, dominating and obliging conflict management styles have been associated with lower job performance among employees (Rahim, Antonioni, \& Psenicka, 2001). Job performance is defined as behaviors or actions that are relevant to the goals of the organization in question (McCloy, Campbell, \& Cudeck, 1994). Somech (2008) found that there was a positive relationship found between integrating CMS and team performance and a negative relation between dominating CMS and team performance. The stress level of employees has also been found to influence employee job performance (Chen, 2009).

\section{PURPOSE}

The purpose of this cross-sectional, explanatory study was to examine the relationship between the cultural beliefs and CMS of U.S. Jamaican immigrants, and their job satisfaction and job performance in the workplace. The three research hypotheses tested were:

$\boldsymbol{H}_{1}$ : There is a positive relationship between the job satisfaction and job performance of U.S. Jamaican immigrants.

$\mathrm{H}_{2}$ : The cultural beliefs of a U.S. Jamaican immigrant will significantly predict their conflict management styles.

$\boldsymbol{H}_{3}:$ For U.S. Jamaican immigrants, conflict management styles will moderate the relationship between job satisfaction and job performance such that this association will be stronger when compromising or integrating CMS is used and weaker when avoiding, dominating or obliging CMS are used.

\section{METHOD}

A cross-sectional, explanatory design was used in this research. This type of quantitative research design, although not appropriate for determining cause-and-effect relationships, is consistent with much of the exploratory research being conducted currently in organizations where theoretically relevant variables are used to predict organizational outcomes (Vogt \& Johnson, 2015).

\section{Population and Sample}

We carry forward this research by focusing on Jamaican immigrants, an understudied group that has relatively large populations in the U.S., Canada and U.K. (Hall, 2010).

In the U.S., there are approximately 965,355 (46.6\% male and 53.4\% female) Jamaican immigrants, with 246,478 Jamaican immigrants living in Florida and 305,285 living in New York (U.S. Census, 2011).

Participants were sought from professional organizations in New York and Florida (the two largest concentrations of Jamaicans living in the U.S.; U.S. Census, 2011): The Florida Education Association, New York State Nursing Association (NYSNA), Jamaica Nurses' Association of Florida, The Caribbean American Business Association, African American/Caribbean Education Association, American Friends of Jamaica and the Caribbean American Medical \& Scientific Association. Social media (Twitter, Facebook, LinkedIn) were also used to secure participants.

Of the 135 who agreed to participate $(N=135)$, there were $104(77.0 \%)$ female and $31(23.0 \%)$ male participants. As for ethnicity, $74.8 \%(n=101)$ indicated that they would use Jamaican to describe 
themselves. Other words selected to describe their ethnicity included, Indian Jamaican/Indo-Jamaican, White Jamaican, and Other. A frequency analysis of age indicated that $21.55 \%(n=29)$ belonged to the 25-34 age group, $51.1 \%(n=69)$ to the $35-44$ group, $21.5 \%(n=29)$ to the $45-54$ group and $5.9 \%(n=8)$. Employment status was as follows: $82 \%(n=109)$ were employed for wages, $13.5 \%(n=18)$ were selfemployed and 3\% $(n=3)$ were students. Approximately 2.0\% $(n=2)$ had data missing for this question.

\section{Research Measures}

The survey consisted of five separate parts: (1) demographics (2) cultural beliefs, (3) conflict management styles, (4) job satisfaction and (5) job performance. All the measures in this study were well researched by a wide range of scholars and the reliability and validity of each measure had been tested extensively.

\section{Demographics}

Questions 1 through 4 collected information on the participant's gender, ethnicity, age, and location. Question 5 collected information on the participant's employment status.

\section{Cultural Beliefs}

Cultural beliefs were measured using the 40-item short version of the Social Axioms Survey (SAS) that measures an individual's social beliefs along five dimensions (Leung et al., 2002). The five dimensions are: control by fate, reward for application, social flexibility, social cynicism, and spirituality. Participants using a 5-point Likert scale responded to the 40 statements and rated the degree to which they believed each of the statements to be true. Responses ranged from 'strongly disbelieve' to 'strongly believe.' Each additive subscale consisted of eight items.

To measure Control by Fate, a sample statement included, 'Good luck follows if one survives a disaster'. To measure reward for application, a sample statement included, 'Every problem has a solution.' A sample statement measuring social flexibility was 'A modest person can make a good impression on people.' An example of a social cynicism item was 'Power and status make people arrogant.' To measure spirituality, an example was 'Belief in a religion helps one understand the meaning of life.'

Prior research has identified Cronbach's alphas for the subscales ranging from $.54-.76$ (Singelis, Hubbard, Her, \& An, 2003). For the current study, the Cronbach's alphas were $.71, .81, .78, .84$ and .73, respectively, which are all above the minimum alpha recommend by Tabachnick \& Fidell (1989) for research measures.

\section{Conflict Management Style}

The 28-item self-report instrument, The Rahim Organizational Conflict Inventory - II (ROCI - II), was used to measure CMS (Rahim, 1983b). ROCI - II uses participant responses to a 5-point Likert-type scale ranging from 'strongly disagree' to 'strongly agree' to measure the five styles of handling interpersonal conflict with superiors, subordinates, and peers (Rahim, 2010). Responses to items are added to create subscale scores, with a higher score indicating a greater amount or use of one of the five CMS: accommodating, avoiding, collaborating, competing, and compromising.

The accommodating subscale consists of six items (e.g. 'I generally try to satisfy the needs of my supervisor'), the avoiding subscale contains six items (e.g. 'I try to stay away from disagreement with my supervisor'), the collaborating subscale contains seven items (e.g. 'I try to investigate an issue with my supervisor to find a solution acceptable to us'), the competing subscale contains five items (e.g. 'I use my influence to get my ideas accepted'), and the compromising subscale contains four items (e.g. 'I try to find a middle course to resolve an impasse'). The Cronbach's $\alpha$ s were $0.83,0.72,0.84,0.78$ and 0.65, respectively. 


\section{Job Satisfaction}

The Job in General Scale (JIG) and the Job Descriptive Index (JDI) (Smith et al., 1987) were used to measure job satisfaction. All scale scores were additive. On the JIG subscale, participants were asked to think about their job in general and what it is like most of the time, and describe it using sample phrases or words that included 'pleasant,' 'worthwhile' and 'poor.' Negatively worded items on the JIG included 'bad,' 'rotten' and 'disagreeable.' The Cronbach's alpha was $\alpha=.93$.

The JDI measured the participant's short-term satisfaction within five facets of their job: People on your present job (COWORKER), Work on Present Job (WORKONPRESENTJOB), Pay (PAY), Opportunities for Promotion (OPPORTUNITIESFORPROMOTION) and Supervision (SUPERVISION). Individuals responded to whether a series of adjectives or brief phrases described his or her job. In completing the instrument, respondents replied '(Y) Yes,' 'Not Sure (?)' or 'No (N).' Some items for the subscale measuring job satisfaction on the both the JDI and JIG contained negatively worded items and were reverse-scored. The negatively worded items on the JDI, for example, included the items measuring WORK like "routine," "dull" and "uninteresting." Sample items on the JDI measuring WORKONPRESENTJOB, asked the respondent how the phrases 'exciting,' 'creative,' or 'boring' described their current work. The Cronbach's alphas for the subscales ranged from .90 to .94 and are presented below in Table 1.

TABLE 1 CRONBACH'S ALPHAS OF SATISFACTION SUBSCALES

\begin{tabular}{lll}
\hline Subscale & $\alpha$ & $N$ \\
\hline JOBINGENERAL & .93 & 108 \\
PAY & .90 & 100 \\
COWORKER & .92 & 108 \\
OPPORTUNITIESFORPROMOTION & .94 & 106 \\
SUPERVISION & .91 & 106 \\
WORKONPRESENTJOB & .91 & 100 \\
\hline
\end{tabular}

\section{Job Performance}

The additive, 11-item self-report questionnaire developed by Kidd (2006) was used to measure job performance. Job performance was measured along two dimensions: contextual performance (6 items) and task performance (5 items). Overall Job Performance was the sum of the all the 11 items.

Participants using a 5-point Likert scale indicated how they perceived themselves in comparison to others in their organization. Responses ranged from 'not at all likely' to 'extremely likely.' To measure task performance, sample statements included 'Plan your work' and 'Look for challenging assignment/task.' For measuring contextual performance, participants compared themselves to other individuals in their organization and indicated how likely it was that they would for example 'Support and encourage a coworker with a problem' and 'Work well with others.' The Cronbach's alphas for task, contextual, and overall performance were $.86, .77$, and .88 , respectively.

\section{Procedures}

Dillman, Smyth, and Christian's (2009) Tailored Design Method was used in the administration of the survey, as it has been shown to be a reliable means of maximizing response rates in internet-based survey studies.

To initiate the study, a panel of two human resource development experts were asked to review the survey for content validity. As a result of their recommendations, the ethnicity question was added and the choices for employment status increased (adding unable to work as an option). 
The initial pilot study was completed with eight participants. This group included an expert in survey design, U.S. Jamaican immigrants, U.S. Citizens and a Jamaican national still residing in Jamaica. There were no significant changes made to the survey following the pilot study.

Once the pilot test was completed, email surveys were sent to the six aforementioned professional organizations and simultaneously posts were made on Twitter, Facebook, and LinkedIn to recruit participants. Potential participants in professional groups were also asked to share with other U.S. Jamaican immigrants. This process was repeated once per week for three weeks.

At the end of the data collection period, the survey was closed and data downloaded from Qualtrics ${ }^{\circledR}$, the data collection platform, for analysis. As is common in internet-based survey studies like this research, there was no way to determine how many prospective participants were contacted and therefore response rates were impossible to calculate (Dillman et al., 2009).

\section{RESULTS}

The following two sections represent the descriptive statistics related to job satisfaction and job performance (see Table 2).

\section{Job Satisfaction}

Stanton and Crossley (2000) indicated that mean scores around 23 - 27 would suggest that respondents were "neither satisfied or dissatisfied" with their jobs, while scores well above 27 would indicate that participants were satisfied with their current job. By these evaluative criteria, participants in this study reported that they had a relatively high level of overall job satisfaction (as reported by JIG scores, which had a mean of 41.33). When it came to four of the other five facets of job satisfaction (COWORKER, PAY, SUPERVISION, and WORK), these means were also well over 27. On the other hand, PROMOTION (opportunities for promotion), demonstrated an appreciably lower mean score of 25.13. This indicates that participants were neither dissatisfied or satisfied with opportunities for promotion on their current jobs. Participants were very satisfied with the supervision they were receiving (SUPERVISION mean score of 41.06); and less satisfied with the work (WORK; mean score of 38.03) they were performing on their current jobs. However, when it came to the pay (PAY; mean score of 32.83) that they were receiving for their current job, participants were somewhat less satisfied as compared to all but the PROMOTION variable.

\section{Job Performance}

The mean score contextual performance (CONTEXTUAL) was $25.16(S D=3.71)$ and TASK performance had a mean score of $19.45(S D=4.51)$. Further, Total or Overall Job Performance had a mean score of $44.62(S D=7.58)$. 
TABLE 2

DESCRIPTIVE STATISTICS - STUDY VARIABLES

\begin{tabular}{lllll}
\hline Variable & $N$ & Mean & Median & $S D$ \\
\hline CONTROLBYFATE & 130 & 13.33 & 13.00 & 4.20 \\
REWARDFORAPPPLICATION & 130 & 25.35 & 26.00 & 4.25 \\
SOCIALCYNICISM & 123 & 33.50 & 34.00 & 8.20 \\
SOCIALFLEXIBILITY & 123 & 30.20 & 30.00 & 2.95 \\
SPIRITUALITY & 123 & 32.50 & 32.00 & 5.87 \\
COWORKER & 108 & 41.21 & 46.00 & 13.83 \\
PAY & 106 & 32.83 & 36.00 & 18.70 \\
PROMOTION & 106 & 25.13 & 21.00 & 20.95 \\
SUPERVISION & 106 & 41.06 & 47.00 & 13.79 \\
WORK & 106 & 38.03 & 42.00 & 14.01 \\
JIG & 108 & 41.33 & 47.00 & 13.86 \\
ACCOMMODATING & 114 & 3.55 & 3.66 & .65 \\
AVOIDING & 114 & 3.27 & 3.33 & .76 \\
COLLABORATING & 114 & 4.17 & 4.14 & .54 \\
COMPETING & 114 & 3.08 & 3.10 & .79 \\
COMPROMISING & 114 & 3.99 & 4.00 & .53 \\
CONTEXTUAL & 104 & 25.16 & 25.00 & 3.71 \\
TASK & 104 & 19.45 & 20.00 & 4.51 \\
TOTALJP & 104 & 44.62 & 45.00 & 7.58 \\
& & & & \\
\hline
\end{tabular}

\section{Data Analyses}

The following sections describe the statistical analyses that were completed. Preliminary correlational analyses were followed by the multiple regressions to test the hypotheses.

\section{Testing the Research Hypotheses}

For each of the research variables, the actual number of participants varied because of incomplete data. As directed by Tabachnick and Fidell (1989), the listwise deletion procedure was used because over $10 \%$ of the data was missing for the job performance variables.

$\mathrm{H}_{1}$ : There is a positive relationship between the perceived job satisfaction and perceived job performance of U.S. Jamaican immigrants.

First, to investigate the relationship between the job satisfaction and job performance variables preliminarily, a correlation ( $r$ ) was computed among the variables. The Pearson's correlation $(r)$ between JIG overall satisfaction, the six facets of the JDI, and TASK, CONTEXTUAL and overall job performance are presented in Table 3.

In general, the positive correlations were in the strength and direction as expected. Interestingly, however, the PAY and PROMOTION satisfaction variables did not correlate significantly with any of the job performance scales. Thus, overall, these results suggest modest to strong correlations among a number of this study's satisfaction and performance variables, preliminarily supporting the first hypothesis.

Table 3. 
TABLE 3

CORRELATIONS AMONG JIG/JDI FACETS, AND PERFORMANCE

\begin{tabular}{cccc}
\hline Variables & TASK & CONTEXTUAL & TOTALJP \\
& $r$ & $r$ & $r$ \\
\hline JOBINGENERAL & $.427 * * *$ & $.352 * * *$ & $.426 * * *$ \\
COWORKERS & $.207 *$ & .091 & .168 \\
WORK & $.327^{* * *}$ & $.269 *$ & $.326^{* *}$ \\
PAY & .156 & .107 & .145 \\
PROMOTION & .147 & .118 & .145 \\
SUPERVISION & $.265^{*}$ & .183 & .248 \\
TASK & 1.00 & $.699 * * *$ & $.937 * * *$ \\
CONTEXTUAL & $.699 * * *$ & 1.00 & $.905^{* * *}$ \\
TOTALJP & .937 & .905 & 1.00 \\
& & &
\end{tabular}

To test $H_{1}$, a multiple regression analysis was conducted to test the degree job satisfaction predicted job performance. The JOBPERFORMANCE scale included two subscales, TASK and CONTEXTUAL. Job Satisfaction's scale as mentioned earlier included six subscales, JIG, PAY, PROMOTION, COWORKER, WORK and SUPERVISION. The effect sizes $\left(R^{2}\right)$ for both regression equations were moderate (Tabachnick \& Fidell, 1989).

In the case of predicting TASK performance, $R^{2}=.207, R_{\text {adj }}^{2}=.157, F(6,97)=4.207, p<.005$; WORK satisfaction was the sole significant predictor of TASK $F(6,97)=4.207, p<.005$. Thus, none of the other five job satisfaction predictors (JIG, PAY, PROMOTION, COWORKER, and SUPERVISION) added significance incremental variance to the regression equation (all $p \mathrm{~s}>.05$ ). Likewise, for CONTEXTUAL performance $R^{2}=.164, R_{\text {adj }}^{2}=.113, F(6,97)=3.180, p<.005$; WORK satisfaction alone also significantly predicted the dependent variable $F(6,97)=3.180, p<.005$, whereas the other five predictors (JIG, PAY, PROMOTION, COWORKER, WORK and SUPERVISION) did not (all $p s>$ .05 ). Based on the regression analysis results, therefore, the first hypothesis was partially supported.

$\boldsymbol{H}_{2}$ : The cultural beliefs of U.S. Jamaican immigrants will predict their conflict management styles.

To test $\mathrm{H}_{2}$, a multiple regression analysis was completed to test the relation between the five subscale scores that measure cultural beliefs and each of the five conflict management styles.

REWARDFORAPPLICATION $(\beta=.193)$ and SPIRITUALITY $(\beta=.202)$ were found to be significant positive predictors of Accommodating style $R^{2}=.129, R_{\text {adj }}^{2}=.089, F(5,108)=3.194, p<.05$.

While REWARDFORAPPLICATION $(\beta=.199)$ was found to be a significant positive predictor for Collaborating style $R^{2}=.157, R_{\text {adj }}^{2}=.118, F(5,108)=4.033, p<.005$, SOCIALCYNICISM $(\beta=-.215)$ was found to be a significant negative predictor for Collaborating style $R^{2}=.157, R_{\text {adj }}^{2}=.118, F(5,108)=$ 4.033, $p<.005$. Further, CONTROLBYFATE $(\beta=.309)$ was found to be a significant positive predictor of Competing style $R^{2}=.150, R_{\text {adj }}^{2}=.110, F(5,108)=3.803, p<.005$.

SOCIALCYNICISM $(\beta=3.07)$, was found to be significant positive predictor of Avoiding style $R^{2}=$ $\left..122, R_{\text {adj }}^{2}=.081, F(5,108)=2.995, p<.05\right]$ And finally, when the regression analysis was completed for Compromising style, $R^{2}=.090, R_{\text {adj }}^{2}=.1048, F(5,108)=3.803, p>.005$, SOCIALFLEXIBILITY $(\beta=$ 2.41) was found to be a significant positive predictor.

Thus, the regression analysis results revealed partial support for the second hypothesis, meaning that cultural beliefs do significantly predict conflict management styles. 
$\boldsymbol{H}_{3}:$ For U.S. Jamaican immigrants, conflict management styles will moderate the relationship between perceived job satisfaction and perceived job performance such that this association will be stronger when compromising or collaborating (integrating) is used and weaker when avoiding, competing (dominating) or accommodating (obliging) conflict management styles are used.

To test $\mathrm{H}_{3}$, moderated multiple regression analyses were conducted to determine if the relationship between Job Satisfaction (i.e., subscale - JIG) and Job Performance was moderated by each CMS. JIG (overall satisfaction) was selected to further examine the moderating effect of CMS on the relationship between Job Satisfaction and Job Performance because it was found to have the largest correlation with task, contextual and overall job performance. Although not shown here, analysis with Work Satisfaction yielded similar results.

To reduce the likelihood of multicollinearity, the predictor variables were centered by subtracting the mean value of all scores on each predictor variable from each score on that predictor (Bang, Ross, \& Reio, 2013). An interaction term was then computed as a cross-product of the centered predictors; in this case, JIG and each of the CMS subscales. A simple slope analysis was then computed to comprehend the direction of the interaction effect at higher (one standard deviation above the mean) and lower (one standard deviation below the mean) levels of the moderator variables, which was each type of CMS (Bang et al., 2017). The results are presented in Tables 4-6.

For the moderated multiple regression where the criterion variable was Task Performance, each CMS subscale and Overall Satisfaction (JIG) as predictors were entered in the first block, and then each of the five interaction terms were included in the second model. Table 4 presents the results of this moderated multiple regression. None of the CMS moderated the effect of JIG on Task Performance, as shown by an incremental $.4 \%$ increase in total variance explained, which was not statistically significant $(F(5,92)=$ $.09, p=.994)$.

The moderated multiple regression where the criterion variable was Contextual Performance, each CMS and the JIG as predictors were entered in the first block, and then each of the five interaction terms were included in the second model. Table 5 presents the results of this moderated multiple regression. The compromising CMS moderated the association between JIG and Contextual Performance, as evidenced by a $9.6 \%$ increase in total variance explained $(F(5,92)=2.65, p<.05)$. This means that the relation between job satisfaction and contextual performance was strengthened when using the compromising CMS.

Finally, for the moderated multiple regression where the criterion variable was Overall Job Performance, each CMS and JIG as predictors were entered first, and then each of the five interaction terms were included in the second model. Table 6 presents the results of this moderated multiple regression. The compromising CMS moderated the association between JIG and Overall Job Performance, as corroborated by a 3.0\% increase in total variance explained, $(F(5,92)=0.78, p<.05)$. Thus, the association between job satisfaction and overall job performance was strengthened when using the compromising conflict management style.

Inasmuch as the compromising CMS positively moderated the association between job satisfaction and both contextual and overall job performance, this hypothesis was partially supported. What this means is when using a compromising CMS by the Jamaicans in this research, the positive relationship between job satisfaction and job performance was strengthened significantly. 
TABLE 4

MODERATED REGRESSION RESULTS OF EFFECTS OF CONFLICT MANAGEMENT STYLE VARIABLES ON THE RELATIONSHIP BETWEEN OVERALL JOB SATISFACTION AND TASK PERFORMANCE

\begin{tabular}{|c|c|c|c|c|c|c|c|}
\hline Variables entered & $R^{2}$ & $F$ & $d f$ & $R^{2}$ change & Beta & $S E$ & $t$ \\
\hline Model 1 & 0.22 & $4.70 * * *$ & 6,97 & 0.225 & & & \\
\hline (Constant) & & & & & & 4.84 & 1.43 \\
\hline Collaborating & & & & & 0.23 & 1.08 & $1.75^{*}$ \\
\hline Accommodating & & & & & 0.24 & 0.75 & $2.23 * *$ \\
\hline Competing & & & & & 0.07 & 0.52 & 0.84 \\
\hline Avoiding & & & & & -0.12 & 0.60 & -1.19 \\
\hline Compromising & & & & & -0.08 & 0.94 & -0.71 \\
\hline JIG & & & & & 0.17 & 0.03 & $1.68 *$ \\
\hline Model 2 & 0.23 & 0.09 & 5,92 & .004 & & & \\
\hline (Constant) & & & & & & 23.58 & 0.55 \\
\hline Collaborating & & & & & 0.17 & 3.40 & 0.40 \\
\hline Accommodating & & & & & 0.41 & 2.89 & 0.97 \\
\hline Competing & & & & & 0.10 & 2.25 & 0.25 \\
\hline Avoiding & & & & & -0.27 & 3.18 & -0.50 \\
\hline Compromising & & & & & -0.24 & 2.60 & -0.79 \\
\hline JIG & & & & & -0.23 & 0.50 & -0.15 \\
\hline Collaborating $\times$ JIG & & & & & 0.12 & 0.08 & 0.11 \\
\hline Accommodating $\times \mathrm{JIG}$ & & & & & -0.33 & 0.06 & -0.39 \\
\hline Competing $\times$ JIG & & & & & -0.05 & 0.05 & -0.08 \\
\hline Avoiding $\times$ JIG & & & & & 0.23 & 0.07 & 0.27 \\
\hline Compromising $\mathrm{x}$ JIG & & & & & 0.50 & 0.06 & 0.57 \\
\hline
\end{tabular}

Note. ${ }^{*} p<.05 ; * * p<.01 ; * * * p<.001$ 
TABLE 5

MODERATED REGRESSION RESULTS OF EFFECTS OF CONFLICT MANAGEMENT STYLE VARIABLES ON THE RELATIONSHIP BETWEEN OVERALL JOB SATISFACTION AND CONTEXTUAL PERFORMANCE

\begin{tabular}{|c|c|c|c|c|c|c|c|}
\hline Variables entered & $R^{2}$ & $F$ & $d f$ & $R^{2}$ change & Beta & $S E$ & $t$ \\
\hline Model 1 & 0.24 & $5.04 * * *$ & 6,97 & 0.24 & & & \\
\hline (Constant) & & & & & & 3.95 & 2.87 \\
\hline Collaborating & & & & & 0.42 & 0.88 & $3.19 * * *$ \\
\hline Accommodating & & & & & 0.15 & 0.62 & 1.37 \\
\hline Competing & & & & & 0.12 & 0.43 & 1.27 \\
\hline Avoiding & & & & & -0.05 & 0.49 & -0.46 \\
\hline Compromising & & & & & -0.09 & 0.77 & -0.81 \\
\hline JIG & & & & & 0.06 & 0.03 & 0.58 \\
\hline Model 2 & 0.34 & $2.65 * * *$ & 5,92 & 0.10 & & & \\
\hline (Constant) & & & & & & 18.02 & $2.85 * *$ \\
\hline Collaborating & & & & & 0.50 & 2.60 & 1.28 \\
\hline Accommodating & & & & & -0.05 & 2.21 & -0.12 \\
\hline Competing & & & & & -0.35 & 1.72 & -0.95 \\
\hline Avoiding & & & & & -0.70 & 2.43 & -1.38 \\
\hline Compromising & & & & & -0.88 & 1.99 & $-3.14 * * *$ \\
\hline JIG & & & & & -3.40 & 0.38 & $-2.35 * *$ \\
\hline Collaborating $\times$ JIG & & & & & -0.41 & 0.06 & -0.40 \\
\hline Accommodating $\times \mathrm{JIG}$ & & & & & 0.56 & 0.05 & 0.71 \\
\hline Competing $\times$ JIG & & & & & 0.67 & 0.04 & 1.17 \\
\hline Avoiding $\times$ JIG & & & & & 0.92 & 0.05 & 1.17 \\
\hline Compromising x JIG & & & & & 2.47 & 0.05 & $3.09 * *$ \\
\hline
\end{tabular}


TABLE 6

MODERATED REGRESSION RESULTS OF EFFECTS OF CONFLICT MANAGEMENT

STYLE VARIABLES ON THE RELATIONSHIP BETWEEN OVERALL JOB SATISFACTION AND OVERALL PERFORMANCE

\begin{tabular}{|c|c|c|c|c|c|c|c|}
\hline Variables entered & $R^{2}$ & $F$ & $d f$ & $R^{2}$ change & Beta & $S E$ & $t$ \\
\hline Model 1 & 0.27 & $5.82 * * *$ & 6,97 & 0.27 & & & \\
\hline (Constant) & & & & & & 7.92 & $2.30 * *$ \\
\hline Collaborating & & & & & 0.34 & 1.77 & $2.66 * *$ \\
\hline Accommodating & & & & & 0.22 & 1.23 & $2.04 * *$ \\
\hline Competing & & & & & 0.10 & 0.86 & 1.14 \\
\hline Avoiding & & & & & -0.10 & 0.98 & -0.96 \\
\hline Compromising & & & & & -0.09 & 1.55 & -0.84 \\
\hline JIG & & & & & 0.13 & 0.05 & 1.32 \\
\hline Model 2 & 0.30 & $1.78^{*}$ & 5,92 & 0.03 & & & \\
\hline (Constant) & & & & & & 37.91 & $1.70 *$ \\
\hline Collaborating & & & & & 0.34 & 5.47 & 0.86 \\
\hline Accommodating & & & & & 0.22 & 4.65 & 0.55 \\
\hline Competing & & & & & -0.11 & 3.61 & -0.30 \\
\hline Avoiding & & & & & -0.50 & 5.11 & -0.96 \\
\hline Compromising & & & & & -0.57 & 4.18 & $-1.98 *$ \\
\hline JIG & & & & & -1.80 & 0.80 & -1.20 \\
\hline Collaborating $\times$ JIG & & & & & -0.13 & 0.12 & -0.12 \\
\hline Accommodating $\times \mathrm{JIG}$ & & & & & 0.08 & 0.10 & .010 \\
\hline Competing $\times$ JIG & & & & & 0.30 & 0.08 & 0.50 \\
\hline Avoiding $\times$ JIG & & & & & 0.59 & 0.11 & 0.72 \\
\hline Compromising x JIG & & & & & 1.50 & 0.10 & $1.82 *$ \\
\hline
\end{tabular}

Note. ${ }^{*} p<.05 ; * * p<.01 ; * * * p<.001$

\section{DISCUSSION}

The narrative that follows discusses the findings as they relate to the three hypotheses that guided this research. The first hypothesis looked at the degree job satisfaction predicted job performance among the sample of U.S. Jamaican immigrants. The findings suggested that job satisfaction indeed positively predicted task, contextual and overall performance, suggesting that being satisfied was associated with performing better. The findings were consistent with other research examining the relationship between job satisfaction and job performance (e.g., Choi \& Kim, 2012; Wright, Companzano, \& Bonett, 2007). Overall, the job satisfaction of U.S. Jamaican immigrants was related to how well they worked with their coworkers, performed their job duties, and performed overall. The overall job satisfaction variable was also positively and significantly related to coworker relationship satisfaction, the work they were doing, and their pay and supervision.

The second hypothesis tested the relationship between the cultural beliefs of U.S. Jamaican immigrants and their CMS. From the means of the subscales that measured the participants' cultural beliefs, the participants demonstrated a relatively strong belief that people or institutions could not be trusted (i.e., social cynicism). 
Social Cynicism belief was a found to be a significant positive predictor for avoiding CMS. In contrast, Social Cynicism was a found to be a significant negative predictor for collaborating CMS. Thus, the U.S. Jamaican immigrants in this study would be less likely to collaborate with their supervisors or coworkers because of a lack of trust.

The participants overall did not demonstrate high Control by Fate scores, and as such believed that for example, their individual characteristics, such as appearances and date of birth would not affect their fate. Control by Fate was found to be a positive predictor of the competing CMS. This means participants scoring highly on this scale might tend to be more competitive or held their ground during conflict situations. Consequently, although the U.S. Jamaican immigrants did not believe necessarily that people had predetermined life outcomes, they would tend to be competitive when situations in the organization or in relationships with their colleagues that left them feeling that they could not trust the coworker or supervisor.

Interestingly, the participants in this study were more likely to be collaborative when handling conflict in the workplace. Moreover, the participants did not score high on the competing conflict management subscale. This finding varies from research conducted in western organizational settings where individuals are more likely to use the dominating CMS more when handling conflict in the workplace (Morris et al., 1998). Finally, Reward for Application was a positive predictor for collaborative CMS. This indicates when faced with conflict, if for example they thought that they would be rewarded for their hard work, they might be more inclined to integrate their ideas to enable problem solving.

Last, the third hypothesis tested the degree to which CMS moderated the relationship between job satisfaction and job performance. The only statistically significant relationship found was with the compromising CMS. Those U.S. Jamaican immigrants who used this style were more likely to have higher levels of overall job satisfaction, task performance and contextual performance. Specifically, they would be more likely to compromise in the face of conflict for the purpose of supporting and encouraging their coworkers and performing well.

\section{Implications of the Study}

Previous literature on the relationship between the cultural beliefs, CMS, job satisfaction, and job performance variables has been sparse. This study covered new ground regarding the cultural beliefs of U.S. Jamaican immigrants in relation to their CMS and how they were linked to job satisfaction and job performance. This study also extends previous research that investigated the relationship between job satisfaction and job performance, as it looked at the moderating effect of CMS on that relationship.

First, this research supported previous research by Choi \& Kim (2012) and Xiao-Hong et al. (2012) that there is a relationship between job satisfaction and job performance. Being satisfied with coworker relationships, the work they were doing, and their pay and supervision was linked with greater job performance.

Second, this research demonstrated that when participants used the compromising CMS, their job satisfaction more strongly predicted job performance. In addition, the Rahim Organizational Conflict Inventory - II (Rahim, 1983b) demonstrated acceptable reliabilities for each subscale (Tabachnick \& Fidell, 1989), supporting its future use in similar studies. Thus, using the scale to distinguish an individual's CMS, HR professionals might design and provide employee training to help them use compromising CMS in particular to promote higher job satisfaction and performance.

Another implication is that it linked the cultural beliefs of U.S. Jamaican immigrants with their dominant conflict management styles. The dominant CMS of U.S. Jamaican immigrants in this study was collaborating and not dominating, which is typically the dominant CMS in western settings (Morris et al., 1998).

\section{Implications for Practice}

Although this is a correlational study and recommendations for practice must be handled tenatively (Tabachnick \& Fidell, 1989), HR professionals still might use the information gained from this research to inform developing cultural sensitivity trainings that help employees to understand the cultural beliefs of 
U.S. Jamaican immigrants. This training might also be beneficial to those supervising U.S. Jamaican immigrants. The HR professional might also use this information to design training to help U.S. Jamaican immigrants use more compromising CMS when encountering workplace conflict. Compromising CMS positively related to job satisfaction (Xiao-Hong et al., 2012) and as such, by creating this type of training, organizations might see increasing levels of job satisfaction and ultimately job performance.

To increase the overall job satisfaction of their employees and their satisfaction with coworker relationships, pay, work, supervision and opportunities for promotion within the organization, organizations may want to administer the Job in General scale and the Job Descriptive Index combined (Smith et al., 1987). By using the information gleaned from both, organizations might be able to look for new ways to meet the needs of their employees and increase their job satisfaction and performance.

HR professionals looking to improve current employee satisfaction may also collect this information through an e-survey with staff leaving the organization. By gathering data on why employees are leaving the organization, HR professionals can use the information collected to create strategies to improve the job satisfaction of their employees.

\section{Limitations and Recommendations for Future Research}

While this study looked at U.S. Jamaican immigrants, it did not investigate the differences between native-born Jamaican immigrants, and first or second generation U.S. born Jamaican immigrants with regard to the research variables. Their cultural beliefs, for example, may be inherently different; a study that examines either group, or one that compares the two might provide insightful new information for HR researchers about the possible nuances of Jamaican cultural beliefs and their association with important organizational outcomes.

Like many nonexperimental, organizational studies, the data were based on employee self-reports and did not include more objective data from supervisors or colleagues about CMS and job performance. Future studies could incorporate more objective data sources into their designs to increase the study's generalizability. Further, although this research design was consistent with prior internet-based studies (Dillman et al., 2009), future research should be designed where response rates can be calculated to enable testing for possible bias issues. Last, for comparison purposes, it is also suggested this study be extended into organizations located within other countries with relatively large numbers of Jamaican immigrants; for example, Canada, and the United Kingdom.

\section{REFERENCES}

Bang, J., \& Reio, T. G., Jr. (2017). Personal accomplishment, mentoring and creative self-efficacy as predictors of creative work involvement: The moderating roles of positive and negative affect. Journal of Psychology: Interdisciplinary and Applied, 151, 148-170.

Bang, H., Ross, S. D., \& Reio, T. G., Jr. (2013). From motivation to organizational commitment of volunteers in non-profit sport organizations: The role of job satisfaction. Journal of Management Development, 32, 96-112.

Burke, R. J. (1970). Methods of resolving superior-subordinate conflict: The constructive use of subordinate differences and disagreements. Organizational Behavior and Human Performance, 5, 393-411.

Chan, K., Huang, X., \& Ng, P. (2008). Managers' conflict management styles and employee attitudinal outcomes: The mediating role of trust. Asia Pacific Journal of Management, 25, 277-295. doi:10.1007/s10490-007-9037-4

Chen, Y. F. (2009). Job stress and performance: A study of police officers in central Taiwan. Social Behavior and Personality, 37, 1341-1356. doi:10.1016/j.jbusres.2003.10.004.

Choi, H. J., \& Kim, Y. T. (2012). Work-family conflict, work-family facilitation, and job outcomes in the Korean hotel industry. International Journal of Contemporary Hospitality Management, 24, 1011-1028. doi:doi:10.1108/09596111211258892. 
De Dreu, C. K. W., \& Beersma, B. (2005). Conflict in organizations: Beyond effectiveness and performance. European Journal of Work and Organizational Psychology, 14, 105-117.

Dillman, D. A., Smyth, J. D., \& Christian, L. M. (2009). Internet, mail and mixed-mode surveys: The Tailored Design Method ( 3 ed.). New Jersey: John Wiley \& Sons Inc.

Ferguson, G. M., Bornstein, M. H., \& Pottinger, A. M. (2012). Tridimensional acculturation and adaptation among Jamaican adolescent-mother dyads in the United States. Child Development, 83, 1486-1493. doi:10.1111/j.1467-8624.2012.01787.x

Hall, M. L. (2010). Re-constituting place and space: Culture and communication in the construction of a Jamaican transnational identity. Howard Journal of Communications, 21, 119-140. doi:10.1080/10646171003727425.

Hofstede, G. (1980). Culture's consequences, international differences in work-related values. Beverly Hills, Calif:: Sage Publications.

Kaushal, R., \& Kwantes, C. T. (2006). The role of culture and personality in choice of conflict management strategy. International Journal of Intercultural Relations, 30, 579-603.

Kidd, C. A. (2006). An exploration of the impact of employee job satisfaction, affect, and performance on organizational financial performance in the health care industry. Unpublished Graduate Thesis, University of Louisville, Kentucky.

Leung, K., Bond, M. H., de Carrasquel, S. R., Muñoz, C., Hernández, M., Murakami, F., . . \& Singelis, T. M. (2002). Social axioms: The search for universal dimensions of general beliefs about how the world functions. Journal of Cross-Cultural Psychology, 33, 286-302.

Leung, K., Lam, B. C. P., Bond, M. H., Conway, L. G., Gornick, L. J., Amponsah, B., . . \& Zhou, F (2012). Developing and evaluating the social axioms survey in eleven countries: Its relationship with the five-factor model of personality. Journal of Cross-Cultural Psychology, 43(5), 833-857. doi: $10.1177 / 0022022111416361$.

McCloy, R. A., Campbell, J. P., \& Cudeck, R. (1994). A confirmatory test of a model of performance determinants. Journal of Applied Psychology, 79, 493-505. doi:10.1037/0021-9010.74.4.657.

Meyer, S. (2004). Organizational response to conflict: Future conflict and work outcomes. Social Work Research, 28, 183(188).

Morris, M., Williams, K., Leung, R., Larrick, M. T., Mendoza, D., Bhatnagar, J., . . \& Jun-Chen, H. (1998). Conflict management style: Accounting for cross-national differences. Journal of International Business Studies, 29, 729-747.

Ogbu, J. U. (1993). Differences in cultural frame of reference. International Journal of Behavioral Development, 16, 483-506.

Rahim, A. M. (1983a). A measure of styles of handling interpersonal conflict. The Academy of Management Journal, 26, 368-376.

Rahim, M. A. (1983b). Rahim Organizational Conflict Inventory-II. Retrieved from PsycTESTS. doi:http://dx.doi.org/10.1037/t01012-000.

Rahim, A. M. (2011). Managing conflict in organizations (4th ed.). New Brunswick N.J.: Transaction Publishers.

Rahim, A. M., Antonioni, D., \& Psenicka, C. (2001). A structural equations model of leader power, subordinates' styles of handling conflict, and job performance. International Journal of Conflict Management, 12, 191-211.

Reio, T. G., Jr., \& Trudel, J. (2013). Workplace incivility and conflict management style: Predicting job performance, organizational commitment, and turnover intent. International Journal of Adult Vocational Education and Technology, 4, 15-37.

Singelis, T. M., Hubbard, C., Her, P., \& An, S. (2003). Convergent validation of the Social Axioms Survey. Personality and Individual Differences, 34, 269-282. doi:10.1016/s0191-8869(02)000430 .

Smith, P. C., Balzer, W., Brannick, M., Eggleston, S., Gibson, W., Ironson, G., . . \& Whalen, M. (1987). The Revised JDI: A facelift for an old friend. The Industrial-Organizational Psychologist, 24, 3133. 
Somech, A. (2008). Managing conflict in school teams: The impact of task and goal interdependence on conflict management and team effectiveness. Educational Administration Quarterly, 44, 359-390.

Stanton, J. M., \& Crossley, C. D. (2000). Electronic resources for the JDI and JIG. JDI Research Office, Bowling Green State University.

Staw, B. M. (1980). The consequences of turnover. Journal of Occupational Behaviour, 1, 253-273.

Tabachnick, B. G., \& Fidell, L. S. (1989). Using multivariate statistics (2 ed.). New York: HarperCollins.

Taras, V., Kirkman, B. L., \& Steel, P. (2010). Examining the impact of culture's consequences: A threedecade, multilevel, meta-analytic review of Hofstede's cultural value dimensions. Journal of Applied Psychology, 95, 405-439. doi:10.1037/a0018938.

Trudel, J., \& Reio, T. G., Jr. (2011). Managing workplace incivility: The role of conflict management styles - Antecedent or antidote? Human Resource Development Quarterly, 22, 395-423.

U.S. Census, Bureau. (2011). American Community Survey - 2010. Retrieved October 20, 2011

Vogt, W. P., \& Johnson, R. B. (2015). The SAGE dictionary of statistics \& methodology: A nontechnical guide for the social sciences. Thousand Oaks, CA: Sage.

Wang, J., Anne, M., \& McLean, G. N. (2016). Understanding crisis and crisis management: An Indian perspective. Human Resource Development International, 19, 192-208.

Weiss, H. M., \& Cropanzano, R. (1996). Affective events theory: A theoretical discussion of the structure, causes and consequences of affective experiences at work. Research in Organizational Behavior: An Annual Series of Analytical Essays and Critical Reviews, 18, 1-74.

Wright, T. A., Cropanzano, R., \& Bonett, D. G. (2007). The moderating role of employee Positive well being on the relation between job satisfaction and job performance. Journal of Occupational Health Psychology, 12, 93-104. doi:10.1037/1076-8998.12.2.93.

Xiao-Hong, C., Zhao, K., Liu, X., \& Desheng Dash, W. (2012). Improving employees' job satisfaction and innovation performance using conflict management. International Journal of Conflict Management, 23, 151-172. doi:http://dx.doi.org/10.1108/10444061 